\title{
CATVLLVS (CATULO)
}

\section{Henry Campos Vargas*}

\author{
A doña Luciana Sparisci Lovicelli
}

Cayo Valerio Catulo, uno de los más grandes poetas de Roma, nace en fecha no determinada durante el siglo I a. C., una etapa convulsa y llena de importantes transformaciones en la península Itálica.

Oriundo de Verona, decide viajar a Roma para desarrollarse como escritor. Allí crece y madura su genio.

De su vida poco se conoce, salvo lo que puede especularse con fundamento en su obra.

La presente obra procura rendir tributo a la persona de este artista. Con este propósito, se ha procurado ser leal al léxico que lo caracterizó (de donde procede la aparición de algunas vulgaridades), su sintaxis y estilo. Asimismo, se reflejan los registros por él empleados, en particular, las formas clásicas que coexisten junto a algunos arcaísmos y ejemplos del latín vulgar. La alusión a Plauto, Nevio y Calímaco procura recordar su erudición, a la vez que lo posiciona en la literatura de la época.

Este breve drama, histórico, si la licencia es admisible, pretende mostrar las más importantes facetas de su personalidad: jovial, amistoso y coqueto, por un lado, lo que contrasta con la procacidad para con sus enemigos y rivales. Destaca sobremanera la presencia de dos grandes hitos de su vida: el amor por su hermano (cuyo nombre se desconoce en realidad) y el amor por Lesbia (a quien muchos estudiosos identifican con la esposa de un destacado funcionario romano). Ambos han sido engarzados, así como la generalidad de la composición, mediante ciertos anacronismos. 


\section{ACTVS PRĪMVS}

Scaena prīma

(En el Foro romano)

CATVLlVS: Saluē, Gellī.

GELLIVS: Saluus sis. Deī tibi bene faciant.

CATVLLVS: Tibi quoque, amīce mī.

GELLIVS: Dīc, quid egistī hesternā nocte?

CATVLLVS: Fabullus fuit apud mē.

GELLIVS: Fabullum assis aestimō.

(Catulo se ríe)

Puellās, puellās dā mī.

CATVLLVS: Puellae? Mihi tradīdit bellās, formōsās puellās.

GELLIVS: Et ēsum, ut opīnor.

CATVLLVS: Sīc scrīpsī ad eum:

Cēnābis bene, mī Fabulle, apud mē

paucīs, sī tibi dī fauent, diēbus,

sī tēcum attuleris bonam atque magnam

cēnam, nōn sine candidā puellā

et uīnō et sale et omnibus cachinnīs.

GELLIVS: Bene, tibi plaudō.

CATVLLVS: Ego, quod prōmīs̄î, exsolūî. Ded̄̄ sibi unguentum tam suāuis ut rogāret deōs sē facerent tōtum nāsum.

GELLIVS: (Pasa por ahí un conocido de ambos) Mē Castor!

CATVLLVS: Quid olfaciō? Plānē, ecce glōriōsus uentriōsus. Hōc est quod dīcunt, male olet quī semper male olet, sacer ālārum, Caelī Rufe.

GELLIVS: Balnea, ubi sunt balnea?

CATVLLVS: Hāc, curre. (Unas muchachas se acercan). Iubeō uōs saluēre. (a una de ellas) Quid noūî Bella, formōsa! (a otra muchacha) Quanta uenustās! (Gelio parece incómodo).

GALLIVS: Venīte in cubiculum meum.

CATVLLVS: Zēlāsne?

GELLIVS: Quid dīcis?

CATVLLVS: (Le mira el trasero a Gelio) Bonae natēs tibi sunt.

GELLIVS: Hercle!

CATVLLVS: Pedicābō tē.

GELLIVS: Prostibulum populī.

Scaena secunda

(Entra Marco el hermano de Catulo)
CATVLLVS: Quem uideō?

GELLIVS: Quid est?

CATVLLVS: Nōn possum crēdere, frāter, meus frāter Mārcus.

MĀRCVS: Vidē, uidē, uidē... Cāius Valerius Catullus.

CATVLLVS: Dā mī manum tuam, optime uir.

MĀRCVS: Optimus? Hercle! (se lleva la mano al miembro), testēs habeō. Crēdidī salūtāuisse Megadōrum senem aut Plautum aut esse in scaenā Aululariae, sed ecce meus frāter germānus.

CATVLlVS: Auē, spēs omnis domūs nostrae, gaudium meum.

MĀRCVS: Mihi pergrātum est tē salūtāre, Catulle. Iam mollīuistī animum tuum contrā Caesarem?

CATVLLVS: Nīl nimium studeō scīre utrum albus an ater homō sit. Sed, quandō Italiam uēnistī?

MĀRCVS: Praepositiōnem dīc,

CATVLLVS: Num tū grammaticus?

MĀRCVS: Et tū, poēta, semper optimē poēta. Hodiē multō māne uēnī.

CATVLLVS: Quō uādis?

MĀRCVS: Ēo ad domum parentis.

CATVLLVS: Pedibus?

MĀRCVS: Volō ambulāre, crās nāuigābō. Ibō Aegyptum.

CATVLLUS: Quid agēs hāc?

MĀRCVS: Negō otium, negōtiī causā.

CATVLLVS: Negōtia, semper tū et tua negōtia. GELLIVS: Bene.

CATVLLVS: (Observa un ave que vuela hacia la izquierda del escenario) Mārce, retardā discessum, obsecrō.

MĀRCVS: Nequeō.

CATVLLVS: Opportet tē manēre Rōmae.

MĀRCVS: Quia? (Catulo no responde) Tacēs. Dīc mihi līberē.

CATVLLVS: Nōn.

MĀRCVS: (afectando la voz) Nōbis dīcere nē dubitā.

CATVLLVS: Ha!, ha!, loqueris uērōnensiter.

MĀRCVS: Pāce tuā, mī urbāne frāter. 
CATVLLVS: Ā sinistrā parram uīdī.

MĀRCVS: Tua sinistra mea dextera est! Nōlī dare auguria.

CATVLLVS: Frāter, pārē cōnsiliō meī, obsecrō. MĀRCVS: Tacē amābōque. Vīue bene, Catulle. CATVLLVS: In perpetuum, frāter, auē atque ualē.

(Marco se retira)

\section{Scaena tertia}

GELLIVS: Compōne uultum, Catulle.

CATVLLVS: Crēdō rūrsum eum nōn uidēre.

GELLIVS: Tacē, amīce, praestat sperāre, dī semper eum amāuērunt. Sed quid dīcō?, uīue atque ualē. Vidē hāc, rōmānī sumus et tōta terra nostra est.

(Entra Lesbia acompañada por una esclava. Lleva un poemario de Safo, su escava lee para ella en voz baja. Catulo la ve)

CATVLLVS: Heūs! Heūs! Illa mulier, quae est? GELLIVS: Quae?

CATVLLVS: Illa. (en griego, la esclava lee los dos primeros versos de Safo) Ella mī pār esse deae uidētur, (Lesbia dirige su mirada hacia Catulo, la esclava deja de leer) illa, sī fās est, -SERVA: Mea domina, reddit latīnē- superāre dīuās (Lesbia no contesta y continúa su paseo).

CATVLLVS: Graecē legit! Necesse est mē loquī sēcum.

GELLIVS: Manē, manē, amīce. Haec est uxor cōnsulis Quīntī Metellī Celeris, matrōna rōmāna. CATVLLVS: Quid ad mē? Aestimō mūlī.

GELLIVS: Memorā Hortensiam, Iūliam...

CATVLLVS: Quid posunt contrā pulchritūdō sōlis, formae caelī?

Mihi trade eam.

GELLIVS: Nēquāquam.

CATVLLVS: Ergō, $\overline{1}$ domum, labor longa, uīta breuis. (Gelio se retira. Lentamente, Catulo se aproxima. Lesbia descubre la maniobra y despacha a su sirvienta).

LESBIA: Discēde (la esclava asiente con un gesto de su cabeza y se marcha).

CATVLLVS: Tē salūtō, pulchra fēmina.
LESBIA: Auē, Catulle.

CATVLLVS: Mē nōscis?

LESBIA: (sigue caminando) Certē, quī Rōmae nescit Catullum esse, optimum poētam?, quī iniūrātur ipsō Caesarī.

CATVLLVS: Et pessimō Mamurrae, cinaedō Rōmulō, mentulae magnae minācī.

LESBIA: Cicerōnī ūnō.

CATVLLVS: Cum meīs foedīs hendecasyllabīs.

LESBIA: Et cēterīs. Nouum nōmen tibi est, nūdius tertius Cicero tē uocāuit neōtericum.

CATVLLVS: Mihi perīculōsum est scīre optimē graecē. Graecitās, Cicero et sua graecitās.

LESBIA: Vt audīuī, tū quoque loqueris graecē.

CATVLLVS: Quandō?

LESBIA: Trānsdūxistī quid mea serua lēgit in latīnam linguam.

CATVLLVS: Negō, quid dīxī, dīxī meae Lesbiae, id nōn fuit trānsductiō (le toma la mano, ella, suavemente se evade). Et sciō optimē graecē.

LESBIA: Lesbia nōn est uocābulum latīnum.

CATVLLVS: Amor uerbum humānum nōn est, sed dīuīnum.

LESBIA: (suspira) Sed etiam tēla amōris humān̄̄ ipsōs deōs uincere posunt (Se detiene y lo mira). Mihi pergrātum erit esse tuam Lesbiam.

CATVLLVS: Quid dīcam? Tibi respondēre debeō.

LESBIA: Volō esse tuam Lesbiam.

CATVLLVS: Quoque uolō. Amor noster erit amor perennē quī scriptūrus est plus ūnō saeclō (la pareja se toma de las manos y sale caminando).

\section{ACTVS SECVNDVS}

Scaena prīma

(En casa de Catulo)

CATVLLVS: Audī, ocule mī.

LESBIA: Tōta auricula, nōn nāsum...

CATVLLVS: Miser Fabullum.

LESBIA: Fāc.

CATVLLVS: Immortālēs mortālēs sī fore fās inuidēre...

LESBIA: Heū, meās aurēs.

CATVLLVS: Inuidēent omnēs dī Catullum poētam. 
LESBIA: Malus poēta, mālō Naeuium.

CATVLLVS: Mālō tē.

LESBIA: Prae Iouem tē uolō tenēre .

CATVLLVS: Id oportet in uentō et rapidā scrībere aquā.

LESBIA: Mihi iniūriātur.

CATVLLVS: Ignōsce mihi, mellitis ocellī.

Scrīpsī tibi:

Vīuāmus, mea Lesbia, atque amēmus

rūmorēsque senum seuēriōrum

omnēs ūnius aestimēmus assis.

LESBIA: Senēs, cānae senēs omnēs.

CATVLLVS: Cum puerīs puerābusque.

Audī quoque:

Iōcundum, mea uīta, mihi propōnis amōrem...

LESBIA: Hunc nostrum inter nōs perpetuumque fore.

CATVLLVS: Deī magnī, facite ut uērē promittere possit.

LESBIA: Atque id sincērē dīcat ex animō.

CATVLLVS: Vt liceat nōbis perdūcere uīta.

LESBIA: Aeternum hoc sanctae foedus amīcitiae.

CATVLLVS: Amīcitiae?

LESBIA: Sīc dīxī.

CATVLLVS: Mē lūdis.

LESBIA: Tacē, catule meī. Hāc nocte, domī, habēbimus conuiuium. Venī. Tē inuītō ad cēnam.

CATVLLVS: Tibi periculōsum est.

LESBIA: Nōn.

CATVLLVS: Ibō.

LESBIA: Perbene.

CATVLLVS: Sed spondē haud male loquī dē mē. LESBIA: Spondeō.

Scaena segunda

(Unos días después en casa de Catulo)

LESBIA: Vesper adest nostrī amōris.

CATVLLVS: Nūlla potest mulier tantum sē dīcere amātam quamtum tū...
LESBIA: Fatīscor.

CATVLlVS: Causā meī? (Lesbia mira con lujuria a uno de sus esclavos).

LESBIA: Taedet amāre.

CATVLLVS: Quid?

LESBIA: Tū̄ amōris mē taedet

(un largo e incómodo silencio se presenta).

CATVLlVS : Mox Iūnia nūbit Manliō.

Compōnam epithalamium, sicut Battiades

Callimachus. Tē in mente scrībam.

LESBIA: Grātiās tibi agō, sed nōlō. Nimis carmina hodiē habuī.

CATVLLVS: Sīc.

(Ella se prepara para salir)

LESBIA: Ibō ad Capitōlium.

CATVLLVS: Eāmus.

LESBIA: Volō īre sōla (Catulo calla por un momento. Ella va a salir y Catulo trata de acompañarla).

CATVLLVS: Eō tēcum.

LESBIA: Nōn, dīxī irem sōla.

CATVLLVS: Matrōna rōmāna debet...

LESBIA: Matrōna? Vbi? Ha! Ha! Intellege mē:

Rēs tibi habeās.

CATVLLVS: Dīuortium? Marītus nōn sum.

LESBIA: Certē, et negō mē esse tuam uxōrem.

Catulle, audī mē. Praestat tē sūmere tuum

Battiadam et discēdere.

CATVLlVS: Nōn, umquam. Memorā tua sponsa amōris.

LESBIA: Heri, haud hodiē. Ardor fuit.

CATVLLVS: Ardor redēbit.

LESBIA: Tacē.

CATVLLVS: Lesbia, mea Lesbia, dīc amāre mē et perpetuum foedus amōris spondēbō.

LESBIA: Sufficit, actum est. Eō domum.

(Lesbia sale de la escena)

CATVLLVS:

Ōdī et amō, // quāre id faciam // fortassē requīris nesciō sed fierī // sentiō et excrucior.

\section{ACTVS TERTIVS}

Scaena prīma

CAELIVS: Aperī portam, amīce, Caelius sum.

CATVLLVS: Līmen intrā, porta aperītur. (Celio 
entra, trae una carta en su mano derecha)

CATVLLVS: Sīs fēlīx, sīs in amōre potens.

CAELIVS: Vt ualēs?

CATVLLVS: Tantum uīuō, et tū?

CAELIVS: Bene mē habēo.

CATVLLVS: Laetor quod tū ualēs. Quid est? Epistula? Num litterae meae Lesbiae?

\section{CAELIVS: Nōn.}

CATVLLVS: Ergō iubeō ut maneat. Vērē sciō Lesbiam nunc in quadruuī̄s et angiportīs glūbere magnanimī Remī nepōtēs, sed ignōscō ê̄, sīc est. Sed crēdō eam esse cum alterō uirō. Dīc mihi, Cealī, quid agit mea Lesbia, nostra Lesbia? Lesbia mī dīcit semper male nec tacet umquam dē mē; Lesbia mē dispeream nisi amat.

CAELIVS: Tacē, amīce, obsecrō, hic amor, Catulle, tibi molestum est.

CATVLLVS: Respondē mihi, quī est?

CAELIVS: Quīuīs possit.

CATVLLVS: Quōuīs nōmen est.

CAELIVS: Gellius, sibi nōmen est Gellius, antīquus amīcus tuus.

CATVLLVS: Macer, tenuis Gellius, cinaedus, paucus homō. Ille macet quotīdiē et sua rosea labella hībernā fiant candidiōra niue quod fēllat...

CAELIVS: Dā silentium.

CATVLlVS: Dō, dō. Certe, omnia falsa speciēs est. Dā mī epistulam.

CAELIVS: Inconueniens.

CATVLLVS: Cūr?

CAELIVS: Tuus frāter...

CATVLLVS: Quid agit?

CAELIVS: Mortuus est.

CATVLlVS: Nōn, nōn, heū miser indignē frāter adempte mihi, fortūna mihi tētē abstulit ipsum. Dīc quomodō.

CAELIVS: Lege, petō.

CATVLLVS: Nequeō.

CAELIVS: Lītore Rhoeteō sua nāuis naufragāuit. CATVLLVS: Heū, heū, frāter, frāter ūitā amābilior, numquam ego tē aspiciam, at certē semper amābō.

CAELIVS: Inuēnērunt suum corpus sepelīuērunt illīc.
CATVLLVS: Debeō īre ut sē postrēmō dōnārem mūnere mortis. Caelī, cūrā meam domum. Nāuigābō quam prīmum.

CAELIVS: $\overline{\mathrm{I}}$, manēbō hīc. (Catulo va a salir, pero se devuelve para tomar algo).

CATVLlVS: Callimachus et mea carmina superest. (Los toma y se va).

Traducción al español

PRIMER ACTO

Escena primera

(En el Foro romano)

CATULO: ¡Salud! Gelio.

GELIO: Que estés bien. Los dioses te protejan.

CATULO: A ti también, mi amigo.

GELIO: Cuéntame, ¿cómo te fue anoche?

CATULO: Fabulo estuvo en mi casa.

GELIO: ¡Fabulo! Si no vale ni cinco céntimos.

(Catulo se ríe)

Chiquillas, a mí háblame de chiquillas.

CATULO: ¿Chiquillas? Él me presentó chiquillas lindas, hermosas.

GELIO: Y comida, supongo.

CATULO: Tal y como se lo escribí:

Cenarás bien conmigo, Fabulo,

en pocos días, si los dioses te favorecen,

y si contigo trajeras buena y grande

cena, no sin faltar cándidas niñas,

vino, tu sal y todas tus chanzas.

GELIO: Bien, te felicito.

CATULO: Lo que le prometí, lo cumplí. Le he dado un perfume tan exquisito que pedía a los dioses que lo hicieran todo nariz para olerlo.

GELIO: (Pasa por ahí un conocido de ambos) ¡Por Cástor!

CATULO: ¿Qué olfateo? Ciertamente, un fanfarrón y panzón. Esto es lo que dicen, huele mal quien siempre huele mala, el de sobacos desgraciados, Celio Rufo.

GELIO: ¡Un baño! ¿Dónde hay un baño?

CATULO: Por allá, ve a prisa (Unas muchachas se acercan). Buenos días, que estén bien (a una de ellas) ¿Qué hay de nuevo? ¡Bella, preciosa! (a otra) ¡Cuánta belleza! (Gelio parece incómodo) GELIO: Vengan a visitar mi cuarto. 
CATULO: ¿Qué? ¿Estás celoso?

GELIO: ¿Qué dices?

CATULO: (Le mira el trasero a Gelio) ¡Vaya!

Pero si tienes buenas nalgas.

GELIO: ¡Por Hércules!

CATULO: Te voy a coger.

GELIO: ¡Oh!, putillo del pueblo.

Escena segunda

(Entra Marco el hermano de Catulo)

CATULO: ¡Oh! ¿Qué ven mis ojos?

GELIO: ¿Qué pasa?

CATULO: No puedo creerlo, mi hermano, mi hermano Marco.

MARCO: Vaya, vaya vaya... Cayo Valerio Catulo.

CATULO: Dame tu mano, óptimo varón.

MARCO: ¿Óptimo? ¡Por Hércules! (se lleva la mano al miembro), tengo testigos. Por un momento creí que saludaba al viejo Megadoro o a Plauto, o quizá estar en una escena de la Aulularia, mas he aquí a mi hermano fraterno.

CATULO: Ave, esperanza de toda nuestra casa. MARCO: Es un gran placer saludarte, Catulo. ¿Ya has suavizado tu actitud para con César?

CATULO: Para nada me preocupa saber en demasía si ése tipo es blanco o negro. Pero, ¿cuándo Italia arribaste?

MARCO: ¿Y la preposición?

CATULO: ¿Ahora tú de gramático?

MARCO: Y tú, poeta, como siempre, un óptimo poeta. Bueno, hoy llegué muy de mañana.

CATULO: Y ¿adónde vas?

MARCO: Voy a la casa de nuestros padres.

CATULO: ¿A pie?

MARCO: Quiero caminar, mañana zarparé. Iré a Egipto.

CATULO: ¿Qué harás allá?

MARCO: Niego mi ocio por mis negocios.

CATULO: Negocios, siempre tú y tus negocios. GELIO: ¡Bien!

CATULO: (Observa un ave que vuela hacia la izquierda del escenario) Marco, te lo ruego, retarda tu partida.

MARCO: No puedo.
CATULO: Conviene que permanezcas en Roma. MARCO: ¿Por qué? (Catulo no responde) Callas. Háblame con toda tranquilidad.

CATULO: No.

MARCO: (afectando la voz) No dudéis en decírnoslo.

CATULO: Ja, ja, hablas veronense.

MARCO: Con tu permiso, mi urbano hermano.

CATUlO: A mi izquierda vi un ave de mal agüero.

MARCO: ¡Pues tu siniestra es mi diestra! No te metas a agorero.

CATULO: Hermano, sigue mi consejo, te lo ruego.

MARCO: Por favor, cállate y te quiero mucho. Vive bien, Catulo.

CATULO: Salud por siempre, hermano, y que estés bien.

(Marco se retira)

Escena tercera

GELIO: Cambia esa cara, Catulo.

CATULO: Creo que nunca lo volveré a ver.

GELIO: Calla, amigo, es mejor esperar, los dioses siempre lo han protegido. Pero, ¿qué digo?, vive y goza. Mira por allá, somos romanos y todas la tierra nos pertenece.

(Entra Lesbia acompañada por una esclava. Lleva un poemario de Safo, su escava lee para ella en voz baja. Catulo la ve)

CATULO: ¡Hey! ¡Hey! Aquella mujer, ¿quién es? GELIO: ¿Cuál?

CATULO: Aquélla (en griego, la esclava lee los dos primeros versos de Safo). Ella me parece semejante a una diosa, (Lesbia dirige su mirada hacia Catulo, la esclava deja de leer) ella, si posible fuera, -ESCLAVA: Mi señora, él traduce en latín- superar a las diosas (Lesbia no contesta y continúa su paseo).

CATULO: ¡Lee en griego! Es preciso que yo hable con ella.

GELIO: Quieto, quieto, amigo. Ella es la esposa del cónsul Quinto Metelo Céler, es una matrona romana.

CATULO: ¿Y eso qué me importa? A él lo tengo por un mulo.

GELIO: Recuerda a Hortensia y a Julia... 
CATULO: ¿Qué pueden ellas ante la hermosura del sol y la belleza del cielo? Vamos, preséntamela. GELIO: De ninguna manera.

CATULO: Entonces, vete a casa, mi trabajo es largo y la vida es breve. (Gelio se retira. Lentamente, Catulo se aproxima. Lesbia descubre la maniobra y despacha a su sirvienta)

LESBIA: Vete. (La esclava asiente con un gesto de su cabeza y se marcha)

CATULO: Te saludo, hermosa dama.

LESBIA: Ave, Catulo.

CATULO: ¿Me conoces?

LESBIA: (sigue caminando) Ciertamente, ¿alguno no conoce en Roma quién sea Catulo, el mayor poeta?, el que insulta al propio César.

CATULO: Y al detestable Mamurra, ese Rómulo maricón, de gran y temible miembro.

LESBIA: Y al gran Cicerón.

CATULO: Con mis feos endecasílabos.

LESBIA: Y todo tipo de versos. Sabes, desde anteayer tienes un nuevo nombre, Cicerón te llamó "neotérico".

CATULO: Me es peligroso saber tan bien griego. Helenismos, Cicerón y sus helenismos.

LESBIA: Según oí, tú también hablas griego.

CATULO: ¿Cuándo?

LESBIA: Tradujiste al latín lo que mi esclava leyó.

CATULO: No es cierto, lo niego. Lo que dije lo dije a mi lesbia, no fue una traducción. (le toma la mano, ella, suavemente se evade). Conozco perfectamente el griego.

LESBIA: "Lesbia" no es un vocablo latino.

CATULO: Y el amor es una palabra divina, no humana.

LESBIA: (suspira) Sin embargo, los dardos del amor humano pueden vencer a los mismos dioses (Se detiene y lo mira). Para mí sería maravilloso ser tu Lesbia.

CATULO: ¿Qué diré? Debo responderte.

LESBIA: Quiero ser tu Lesbia.

CATULO: Yo también quiero. Nuestro amor será un amor perenne del que se escribirá más allá de nuestra época (la pareja se toma de las manos y sale caminando).

\section{ACTO SEGUNDO}

Escena primera

(En casa de Catulo)

CATULO: Escúchame, ojitos míos.

LESBIA: Soy toda oídos, no narices...

CATULO: ¡Oh! Pobre Fabulo.

LESBIA: Anda, sigue.

CATULO: Si los inmortales a los mortales permitido les fuera envidiar...

LESBIA: ¡Hay!, mis oídos.

CATULO: Envidiarían todos los dioses a Catulo el poeta.

LESBIA: Mal poeta, por cierto, prefiero a Nevio. CATULO: Pues yo te prefiero a ti.

LESBIA: Sabes, quiero tenerte antes que al propio Júpiter.

CATULO: Eso conviene escribirlo en el viento y la rápida agua.

LESBIA: Me ofendes.

CATULO: Discúlpame, ojitos de miel. Mira, te escribí esto:

Vivamos, mi Lesbia, y amemos

y los rumores de los severos ancianos

todos estimémoslos en un céntimo.

LESBIA: Ancianos, todos son unas viejos verdes. CATULO: Con los chiquillos y las chiquillas.

Oye esto también:

Feliz, mi vida, me propones ser tu amor...

LESBIA: Éste que entre nosotros perpetuo será.

CATULO: ¡Oh grandes dioses!, permitid que en verdad prometer pueda.

LESBIA: Y sinceramente lo diga desde el alma.

CATULO: Que se nos permita llevar por toda la vida.

LESBIA: Este perpetuo pacto de santa amistad.

CATULO: ¿De amistad?

LESBIA: Así dije.

CATULO: Me estás vacilando.

LESBIA: Cállate, cachorrito mío. Esta noche tendremos un convivio en casa. Ven. Te invito a cenar.

CATULO: Es peligroso para ti.

LESBIA: No. 
CATULO: Voy a ir.

LESBIA: Muy bien.

CATULO: Pero prométeme que no hablarás mal de mí.

LESBIA: Lo prometo.

Escena segunda

(Unos días después en casa de Catulo)

LESBIA: Se aproxima el atardecer de nuestro amor.

CATULO: Ninguna mujer puede decirse tan amada como tú...

LESBIA: Estoy cansada.

CATULO: ¿De mí? (Lesbia mira con lujuria a uno de sus esclavos).

LESBIA: Amar me hastía.

CATULO: ¿Qué?

LESBIA: Estoy hastiada de tu amor (un largo e incómodo silencio se presenta).

CATULO: Pronto Junia se casará con Manlio. Les compondré un epitalamio, como los del Batiada Calímaco. Lo escribiré contigo en mi mente.

LESBIA: Gracias, pero no quiero. He tenido demasiados poemas por hoy.

CATULO: Así es.

(Ella se prepara para salir)

LESBIA: Iré al Capitolio.

CATULO: Vamos.

LESBIA: Quiero ir sola (Catulo calla por un momento. Ella va a salir y Catulo trata de acompañarla).

CATULO: Voy contigo.

LESBIA: No, dije que iría sola.

CATULO: Una matrona romana debe...

LESBIA: ¿Matrona? ¿Dónde? Ja, ja. Entiéndeme:

Llévate tus cosas de aquí.

CATULO: ¿Un divorcio? No soy tu marido.

LESBIA: Correcto, y rechazo ser tu esposa.

Catulo, escúchame. Es mejor que tomes a tu Batiada y te vayas.

CATULO: No, jamás. Recuerda tus promesas de amor.

LESBIA: Ayer, no hoy. Fue la pasión.

CATULO: La pasión volverá.

LESBIA: Calla.

CATULO: Lesbia, mi Lesbia, di que me amas y te ofreceré un perpetuo pacto de amor.

LESBIA: ¡Es suficiente! Se acabó. Me voy a casa.

(Lesbia sale de la escena)

CATULO:

Odio y amo, por qué esto haga, quizás preguntes, no sé, pero siento que acontence y me atormento.

\section{ACTO TERCERO}

Escena primera

CELIO: Abre la puerta, amigo, soy Celio.

CATULO: Entra, la puerta está abierta.

(Celio entra, trae una carta en su mano derecha)

CATULO: Que seas feliz y muy próspero en el amor.

CELIO: ¿Cómo estás?

CATULO: Sobrevivo, ¿y tú?

CELIO: Estoy bien.

CATULO: Me alegro de que estés bien. ¿Qué es eso? ¿Una carta? ¿Acaso palabras de mi Lesbia? CELIO: No.

CATULO: Entonces dispongo que espere. En verdad, sé que Lesbia en las esquinas y encrucijadas se traga a todos los descendientes de Remo, pero la perdono, así es ella. Pero creo que ella anda con otro hombre. Dime, Celio, ¿qué hace mi Lesbia, nuestra Lesbia? Sabes, Lesbia siempre me habla mal y nunca deja de hablar de mí; que me trague la tierra si ella no me ama.

CELIO: Calla, amigo, te lo ruego, Catulo, este amor te perjudica.

CATULO: Respóndeme, ¿quién es?

CELIO: Podría ser cualquiera.

CATULO: Ese cualquiera tiene nombre.

CELIO: Gelio, se llama Gelio, tu antiguo amigo. CATULO: El flaco y jalado Gelio, ese maricón, poco hombre. Ese todo los días enflaquece y sus rosados labios se hacen más blancos que la nieve porque se está chupando a...

CELIO: Haz silencio.

CATULO: Lo hago, lo hago. En verdad, todo es un espejismo. Dame esa carta.

CELIO: No es conveniente.

CATULO: ¿Por qué?

CELIO: Tu hermano...

CATULO: ¿Qué le pasó? 
CELIO: Ha muerto.

CATUlO: No, no, ¡hay! Pobre hermano, indignamente arrebatado, el destino teme quitó. Dime cómo ocurrió.

CELIO: Lee, por favor.

CATULO: No puedo.

CELIO: En el litoral reteo naufragó su barco.

CATULO: ¡Hay! ¡Hay!, hermano, hermano más querido que mi vida, nunca te volveré a ver, mas ciertamente por siempre te amaré.
CELIO: Encontraron su cuerpo y lo sepultaron allá.

CATULO: Debo ir para cumplir con mis postreros deberes. Celio, cuida mi casa. Zarparé cuanto antes.

CELIO: Ve, me quedaré aquí.

(Catulo va a salir, pero se devuelve para tomar algo).

CATULO: Calímaco y mis poesías son lo único que me queda. (Los toma y se va).

FIN

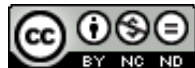

Este obra está bajo una licencia de Creative Commons Reconocimiento-NoComercial-SinObraDerivada 4.0 Internacional. 
